\title{
THE VALUE OF THE ANKYLOSING SPONDYLITIS DISEASE ACTIVITY SCORE (ASDAS) IN EVALUATING DISEASE ACTIVITY IN PATIENTS WITH AXIAL SPONDYLOARTHRITIS
}

\author{
Laura Muntean ${ }^{1}$, Madalina Valeanu ${ }^{2}$, Andreea Lungu ${ }^{1}$, Ioana Felea ${ }^{1}$, Ileana Filipescu ${ }^{1}$, \\ Maria Magdalena Tamas ${ }^{1}$, Raluca Balaj ${ }^{1}$, Linda Ghib ${ }^{1}$, Simon Siao-Pin ${ }^{1}$, Simona Rednic ${ }^{1}$ \\ 'Department of Rheumatology, Iuliu Hatieganu University of Medicine and Pharmacy, Cluj-Napoca, \\ Romania \\ ${ }^{2}$ Department of Medical Informatics and Biostatistics, \\ Iuliu Hatieganu University of Medicine and Pharmacy, Cluj-Napoca, Romania
}

\begin{abstract}
Aim. To evaluate the clinical value of the Ankylosing Spondylitis Disease Activity Score (ASDAS) in assessing disease activity in axial SpA patients in comparison with conventional clinical measures of disease activity in daily clinical practice.

Patients and methods. Eighty-five patients with axial SpA were included in a cross-sectional study. Disease activity was assessed by Bath Ankylosing Spondylitis Disease Activity (BASDAI) score, ASDAS score with C-reactive protein (ASDAS-CRP), ASDAS score with erythrocyte sedimentation rate (ASDAS-ESR), patient's global assessment of disease activity (PtGA), CRP and ESR, while physical function was evaluated by the Bath Ankylosing Spondylitis Functional Index (BASFI). The correlation between different markers of disease activity and functional capacity and ASDAS scores were determined. Patients were grouped into high and low disease activity states according to PtGA scores, CRP levels and BASDAI scores. We compared the discriminating ability of the two ASDAS versions and the conventional clinical measures of disease activity in differentiating between patients with high and low disease activity by using standardized mean differences and receiver operating characteristic (ROC) curve analysis.

Results. ASDAS-CRP and ASDAS-ESR showed good correlation with BASDAI ( $r=0.84$ and 0.72 , respectively), $\operatorname{PtGA}(r=0.82$ and 0.74 , respectively), and BASFI ( $r=0.74$ and 0.70 , respectively). Moderate correlations were seen between the two ASDAS versions and ESR and CRP ( $r$ ranged from 0.43 to 0.70 ). The ASDAS versions had higher discriminating capacities as compared to conventional patient-reported measures (BASDAl and PtGA) and objective markers of disease activity (CRP and ESR). The ASDAS-CRP performed better than ASDAS-ESR. Both ASDAS versions and BASDAl had high areas under the curve (AUC) according to PtGA and CRP levels (AUC ranged from 0.66 to 0.92 , all $p<0.01$ ). The calculated cut-offs for discriminating between disease activity states in our axSpA patients were relatively similar to the Assessment of Spondyloarthritis International Society (ASAS) endorsed cut-offs.

Conclusions. ASDAS versions had higher discriminating ability in patients with axSpA in terms of high and low disease activity states than conventional measures. These findings suggest that ASDAS is a valid and reliable assessment tool for axial SpA patients in daily clinical practice.
\end{abstract}

Keywords: axial spondyloarthritis, ASDAS, BASDAI, patient global assessment, disease activity

\section{INTRODUCTION}

Axial spondyloarthritides (axSpA) are immune mediated disorders that cause chronic inflammation mainly in the sacroiliac joints and axial skeleton, in addition with a wide variety of other musculoskeletal and extra-articular manifestations (1). AxSpA have a significant negative impact on the patient's life, consequently several key elements have been established to evaluate the patient: disease activity, function, spinal mobility, structural damage, and quality of life (2). These elements should accurately reflect the patient's state and should be easy to use in daily clinical practice. In what concerns assessing 
disease activity, no gold standard measure has been found because of the complexity and heterogeneity of axSpA. The conventional measures used in clinical practice are either single-item measures like pain, stiffness, patient global assessment (PtGA) and physician global assessment (PGA), acute-phase reactants, or composite indices like Bath Ankylosing Spondylitis Disease Activity (BASDAI) score $(3,4)$. The aforementioned indices have certain limitations because they measure only part of disease activity and are fully patient or physician oriented $(5,6)$.

The Ankylosing Spondylitis Disease Activity Score (ASDAS) is the first validated assessment tool which combines patient-reported measures with acute phase reactants $(6,7)$. It includes the following items: back pain, duration of morning stiffness, peripheral joints pain and/or tumefaction, patient global assessment of disease activity and an acute phase reactant (CRP or ESR). Several studies have shown that ASDAS is highly discriminating in distinguishing patients with different levels of disease activity and is also sensitive to change (8-15). All in all, they concluded that ASDAS performs at least equally well as BASDAI, if not better, hence ASDAS appears to be the best method to use in clinical trials (16). Moreover, there have been studies that have determined ASDAS cut-off values for disease activity states and levels of improvement (17), which proved to have had great clinical value, an accurate assessment of disease activity being central for treatment modifications decisions (18).

It seems that more and more studies report that ASDAS has numerous advantages; however its use in clinical practice requires further assessment. The validity and feasibility of the new instrument needs to be checked in populations with different characteristics than the original population in which the composite index was developed and validated before putting it into service in clinical practice.

The aim of our study is to compare the performance of the ASDAS score and conventional measures of assessing disease activity in axSpA patients in daily clinical practice.

\section{PATIENTS AND METHODS}

\section{Patients}

This cross-sectional study included 85 patients diagnosed with axSpA according to the imaging arm of the new Assessment of Spondyloarthritis International Society (ASAS) criteria (19). They attended our tertiary Rheumatology Unit between September
2014 and April 2015 as inpatients or outpatients. The study was approved by the ethics committee and written informed consent was obtained from all patients according to the Declaration of Helsinki.

\section{Clinical assessment}

The following clinical variables were collected: age, sex, disease duration, age at disease onset, family history, peripheral arthritis, extra-articular manifestations of spondyloarthritis (uveitis, psoriasis, inflammatory bowel disease). We also recorded the patient's medication history within the last 3 months including intermittent or continuous use of non-steroidal anti-inflammatory drugs (NSAIDs), diseasemodifying anti-rheumatic drugs (DMARDs) and anti-TNF $\alpha$ agents. Spinal mobility was assessed by measurement of lumbar flexion (modified Schober's test), lateral spinal flexion, tragus-to-wall distance, cervical rotation, intermalleolar distance. Based on the aforementioned spinal measurements, the Bath Ankylosing Spondylitis Metrology Index (BASMI) was calculated for all patients (20). The patients' function was evaluated by Bath Ankylosing Spondylitis Function Index (BASFI) which consists of 10 questions designed to evaluate the patients' perception of their functional ability and how well they are able to complete the activities of daily living. The mean of the 10 scales indicate the BASFI score, which had a range of 0 to 10 , with higher scores indicating more functional limitation (21). Disease activity was evaluated using several subjective measures including patient's global assessment (PtGA), Bath Ankylosing Spondylitis Disease Activity Index (BASDAI) (22) and Ankylosing Spondylitis Disease Activity Score (ASDAS) (7). PtGA score represents the patient's rating of disease activity on a visual analogue scale (VAS) of $10 \mathrm{~cm}(0=$ not active; $10=$ extremely active). BASDAI is a validated disease activity questionnaire that includes patient-reported assessments of fatigue, back pain, peripheral joint pain and/or swelling, localized tenderness and the severity and duration of morning stiffness. All scores are recorded on a numerical rating scale, ranging from 0 to 10 , with higher scores indicating greater disease activity. Traditionally, a cut-off level of 4 is used to define the presence of an active disease (1). ASDAS is a composite score consisting in three individual questions from the BASDAI, the PGA score, and CRP or ESR. ASDAS was calculated with the following two formulae recommended by ASAS: 
(1) $\mathrm{ASDAS}-\mathrm{CRP}=0.12 \mathrm{x}$ back pain (BASDAI Q2) $+0.06 \mathrm{x}$ duration of morning stiffness (BASDAI Q6) $+0.11 \times$ PGA $+0.07 \times$ peripheral joints pain and/or swelling (BASDAI Q 3) $+0.58 \times \operatorname{Ln}(\mathrm{CRP}+1) ;(2)$ ASDAS $-\mathrm{ESR}=0.08 \times$ back pain $+0.07 \times$ duration of morning stiffness $+0.11 \times$ PGA $+0.09 \times$ peripheral joints pain and/or swelling $+0.29 \times \sqrt{ } \operatorname{ESR}(7)$. Cut-offs values of ASDAS for disease activity states are the following: ASDAS $<1.3$ for inactive disease; $1.3 \leq$ ASDAS $<2.1$, moderate disease activity; $2.1 \leq$ ASDAS $\leq 3.5$, high disease activity; and ASDAS > 3.5 , very high disease activity (17).

In addition, disease activity was assessed by traditional serologic markers of disease activity: the C-reactive protein (CRP) (control reference $<6 \mathrm{mg} / \mathrm{l}$ ) and erythrocyte sedimentation rate (ESR) (control reference $<20 \mathrm{~mm} / \mathrm{hr}$ ).

\section{Statistical analysis}

Normal distribution for quantitative variables was tested by applying Kolmogorov-Smirnov test. Descriptive statistics are presented as mean and standard deviation (SD), median and interquartile range (IR $=75^{\text {th }}-25^{\text {th }}$ percentiles) or frequency (percentage), depending on the type of variable. The Student's $t$ or the Mann-Whitney U tests were used to compare continuous variables between axSpA patient subgroups. The chi-square or the Fisher tests were performed to compare categorical variables. Normally distributed variables were analyzed by the Pearson's test and non-normally distributed variables by the Spearman's rank test. Correlations $\geq$ 0.90 were interpreted as very high, $0.70-0.89$ high, 0.50-0.69 moderate, and 0.25-0.49 low.

AxSpA patients were divided into subgroups of patients with high and low disease activity according to the following parameters: PtGA score $(\geq 5$ for high disease activity versus $<5$ for low disease activity), CRP level ( $\geq 6 \mathrm{mg} / \mathrm{l}$ for high disease activity versus $<6 \mathrm{mg} / \mathrm{l}$ for high disease activity) and BASDAI score $(\geq 4$ for high disease activity versus $<4$ for high disease activity). In order to evaluate and compare the discriminating ability of the composite indices and other markers of disease activity with respect to patient subgroups with high and low disease activity we calculated the standardized mean difference (SMD), which represents the difference of the group means divided by the pooled SD of the group means. The higher the SMD value, the greater the discriminating capacity (7). SMD values were considered to represent good $(\geq 0.80)$, moderate $(0.50$ $0.80)$ or small $(<0.50)$ discriminating power.
ASDAS, BASDAI and other indices optimal cutoffs for discriminating between axSpA patients with high disease activity and those with low disease activity were estimated by plotting receiver operating characteristic (ROC) curves. We also calculated the area under the curve (AUC) in this setting for various indices of disease activity. AUC values $\geq 0.90$ stand for high accuracy, from 0.70 to 0.90 for moderate accuracy, and from 0.50 to 0.70 for poor accuracy.

$\mathrm{P}$-value $<0.05$ was considered statistically significant. Statistical analysis was carried out using SPSS 15.0 (SPSS Inc, Chicago, USA).

\section{RESULTS}

\section{Patient characteristics}

The characteristics of axSpA patients are summarized in Table 1. The study population comprised 85 axSpA patients with mean (SD) age of 40.3 (11.2) and disease duration of 12.1 (8.8) years. Two-third of the patients had a high or very high disease activity state according to ASDAS-CRP cutoff $(\geq 2.1)$ and $60 \%$ of the patients had a BASDAI $\geq 4$, reflecting a cohort with active disease. Seventy-two $(84.7 \%)$ patients had radiographic sacroiliitis and were diagnosed with AS according to New York criteria (23), while $13(15.3 \%)$ patients were classified as nr-axSpA based on the presence of active sacroiliitis on magnetic resonance imaging (MRI) (19). Except for more severe spinal mobility impairment in AS patients, there were no significant differences in demographic, clinical and laboratory characteristics between patients with AS and nr-axSpA (data not shown, all $\mathrm{p}>0.05$ ).

Using BASDAI cut-off 4, we divided patients in low and high activity subgroups. The demographic and clinical variables reflecting disease activity and functional capacity of the axSpA patients in these subgroups are shown in Table 2. Patients with high disease activity (BASDAI $\geq 4$ ) had significantly higher values of PtGA, BASFI and of the two ASDAS versions than those with low disease activity (BASDAI < 4). The means of the ASDAS versions were 4.1 and 3.7 in patients with high disease activity and these values correspond to a PtGA of 6.7.

\section{Correlations with markers of disease activity and functional capacity}

Table 3 shows $r$ coefficients for the correlations between the various disease activity markers and measures of functional capacity in axSpA patients. 
TABLE 1. Characteristics of patients with axial spondyloarthritis $(n=85)$

\begin{tabular}{|l|l|}
\hline Characteristics & $\begin{array}{l}\text { AxSpA } \\
\text { (n =85) }\end{array}$ \\
\hline Age, mean (SD), years & $40.3(11.2)$ \\
\hline Male, $\mathrm{n}(\%)$ & $63(74.1)$ \\
\hline Disease duration, mean (SD), years & $12.1(8.8)$ \\
\hline AS/nr-axSpA, $\mathrm{n}(\%)$ & $72(84.7) / 13(15.3)$ \\
\hline Syndesmophytes, $\mathrm{n}(\%)$ & $32(37.6)$ \\
\hline Peripheral arthritis, $\mathrm{n}(\%)$ & $15(17.6)$ \\
\hline Number of swollen joints, mean (SD) & $1.03(1.5)$ \\
\hline Enthesitis, $\mathrm{n}(\%)$ & $34(40)$ \\
\hline Dactylitis, $\mathrm{n}(\%)$ & $11(12.9)$ \\
\hline Uveitis, $\mathrm{n}(\%)$ & $16(18.8)$ \\
\hline Psoriasis, $\mathrm{n}(\%)$ & $5(5.9)$ \\
\hline IBD, $\mathrm{n}(\%)$ & $5(5.9)$ \\
\hline Family history, $\mathrm{n}(\%)$ & $9(10.6)$ \\
\hline NSAIDs, $\mathrm{n}(\%)$ & $78(91.8)$ \\
\hline DMARDs/anti-TNFa, $\mathrm{n}(\%)$ & $47(55.3) / 14(16.5)$ \\
\hline ESR (mm/h), mean (SD) & $24.2(22.3)$ \\
\hline CRP (mg/l), mean (SD) & $19.2(21.5)$ \\
\hline PtGA (0-10), mean (SD) & $5.9(2.8)$ \\
\hline BASDAI (0-10), mean (SD) & $4.8(2.6)$ \\
\hline BASFI (0-10), mean (SD) & $4.6(2.8)$ \\
\hline BASMI (0-10), mean (SD) & $3.4(2.8)$ \\
\hline ASDAS-ESR, mean (SD) & $3.3(1.2)$ \\
\hline ASDAS-CRP, mean (SD) & $3.1(1.2)$ \\
\hline SD, standard $\%$ (\%) & \\
\hline
\end{tabular}

$\mathrm{SD}$, standard deviation

AS, ankylosing spondylitis; nr-axSpA, non-radiographic axial spondyloarthritis; IBD, inflammatory bowel disease; NSAID, nonsteroidal antiinflammatory drug; DMARDs, disease-modifying anti-rheumatic drugs; TNF $\alpha$, tumour necrosis factor alpha; ESR, Erythrocyte Sedimentation Rate; CRP, C-Reactive Protein; PtGA, Patient Global Assessement; BASDAI, Bath Ankylosing Spondylitis Disease Activity Index; BASFI, Bath Ankylosing Spondylitis Disease Functional Index; BASMI, Bath Ankylosing Spondylitis Metrology Index; ASDAS, Ankylosing Spondylitis Disease Activity Score.

TABLE 2. Characteristics of patients with high and low disease activity according to BASDAl

\begin{tabular}{|l|c|c|c|}
\hline & $\begin{array}{c}\text { Low disease } \\
\text { activity } \\
\text { BASDAI <4 } \\
(\mathbf{n}=\mathbf{3 6})\end{array}$ & $\begin{array}{c}\text { High disease } \\
\text { activity } \\
\text { BASDAI } \geq 4 \\
(\mathbf{n}=\mathbf{4 9 )}\end{array}$ & $\mathbf{p}$ \\
\hline Age, years & $36(15)$ & $40(22)$ & 0.07 \\
\hline Male, $\mathrm{n}(\%)$ & $28(77.8)$ & $35(71.4)$ & 0.51 \\
\hline $\begin{array}{l}\text { Disease } \\
\text { duration, years }\end{array}$ & $8(9.5)$ & $11(11)$ & 0.48 \\
\hline ESR (mm/h) & $15(17)$ & $20(30)$ & 0.35 \\
\hline CRP (mg/l) & $6(8)$ & $14(26)$ & 0.08 \\
\hline PtGA (0-10) & $3(2.5)$ & $8(2)$ & $<0.001$ \\
\hline BASFI (0-10) & $1.5(2.7)$ & $6.2(2.5)$ & $<0.001$ \\
\hline BASMI (0-10) & $2(5)$ & $3(4)$ & 0.87 \\
\hline ASDAS-CRP & $2.2(0.8)$ & $4(1.4)$ & $<0.001$ \\
\hline ASDAS-ESR & $2.1(0.9)$ & $3.7(1.3)$ & $<0.001$ \\
\hline
\end{tabular}

Data are presented as median (IR $=75^{\text {th }}$ percentile $-25^{\text {th }}$ percentile), unless stated otherwise

ESR, Erythrocyte Sedimentation Rate; CRP, C-Reactive Protein; PtGA, Patient Global Assessement; BASDAl, Bath Ankylosing Spondylitis Disease Activity Index; BASFI, Bath Ankylosing Spondylitis Disease Functional Index; BASMI, Bath Ankylosing Spondylitis Metrology Index; ASDAS, Ankylosing Spondylitis Disease Activity Score.
TABLE 3. Correlation coefficients ( $r$ ) between markers of disease activity and severity in axial spondyloarthritis patients $(n=85)$

\begin{tabular}{|l|c|c|}
\hline & ASDAS - CRP & ASDAS -ESR \\
\hline ASDAS - CRP & 1 & $0.87^{* *}$ \\
\hline ASDAS - ESR & $0.87^{* *}$ & 1 \\
\hline BASDAI & $0.84^{* *}$ & $0.72^{* *}$ \\
\hline PGA & $0.82^{* *}$ & $0.74^{* *}$ \\
\hline ESR & $0.43^{* *}$ & $0.70^{* *}$ \\
\hline CRP & $0.54^{* *}$ & $0.50^{* *}$ \\
\hline BASFI & $0.74^{* *}$ & $0.70^{* *}$ \\
\hline BASMI & -0.13 & -0.12 \\
\hline Schober's test & $-0.41^{* *}$ & $-0.34^{* *}$ \\
\hline Lateral flexion & $-0.49^{* *}$ & $-0.40^{* *}$ \\
\hline Tragus-to-wall distance & $0.36^{* *}$ & $0.36^{* *}$ \\
\hline Cervical rotation & $0.49^{* *}$ & $0.49^{* *}$ \\
\hline Intermalleolar distance & $-0.50^{* *}$ & $-0.36^{* *}$ \\
\hline
\end{tabular}

$* * p<0.01$

ASDAS, Ankylosing Spondylitis Disease Activity Score; CRP, C-Reactive Protein; ESR, Erythrocyte Sedimentation Rate; BASDAI, Bath Ankylosing Spondylitis Disease Activity Index; PGA, Patient Global Assessement; BASFI, Bath Ankylosing Spondylitis Disease Functional Index; BASMI, Bath Ankylosing Spondylitis Metrology Index.

Both ASDAS-CRP and ASDAS-ESR showed good correlations with subjective markers of disease activity including BASDAI (0.84 and 0.72, respectively; $\mathrm{p}<0.01)$ and PGA (0.82 and 0.74, respectively, $\mathrm{p}<0.01$ ). They also showed good correlations with functional disability as expressed by BASFI. Moderate correlations were seen between the two ASDAS versions and objective markers of disease activity, ESR and CRP ( $r$ ranged from 0.43 to $0.70, p<0.01$ ). There were no significant correlations between the two ASDAS versions and BASMI $(\mathrm{r}=-0.13, \mathrm{p}=$ 0.37 and $\mathrm{r}=-0.12, \mathrm{p}=0.39$, respectively). However, we found weak to moderate correlations between ASDAS versions and measures of spinal mobility which are included in BASMI ( $\mathrm{r}$ ranged from 0.36 to $0.50, \mathrm{p}<0.01)$. We found a moderate positive correlation between CRP and ESR $(\mathrm{r}=0.52, \mathrm{p}<0.01)$. CRP levels were not correlated with BASDAI $(r=0.19 ; p=0.16)$, PGA $(r=0.17, p=0.19)$ or BASFI $(r=0.18 ; p=0.20)$. ESR levels were correlated significantly with BASFI $(r=0.37, p=0.005)$, but not with BASDAI $(\mathrm{r}=0.16, \mathrm{p}=0.23)$ and PGA $(r=0.21, p=0.10)$. BASDAI correlated significantly with BASFI $(r=0.79, p<0.001)$. We found no correlations between any of the markers of disease activity and age, disease duration or peripheral involvement (data not shown, all $\mathrm{p}>0.05$ ). 


\section{Discrimination between high and low disease activity states}

Table 4 shows the discriminating ability of various markers of disease activity when patients are classified into high and low disease activity states according to their PtGA scores or CRP levels. When PtGA was used as an external criterion for disease activity state, $61 \%$ of axSpA patients had high disease activity (PtGA $\geq 5)$ and $39 \%$ of the patients had low disease activity $(\mathrm{PtGA}<5)$. In patients with high disease activity, according to their own assessment, the means of the ASDAS versions were 3.9 and 3.1, and these values corresponded with a mean BASDAI value of 6.3. The SMDs between disease activity states showed that both ASDAS-CRP and ASDAS-ESR had very good discriminating abilities, with ASDAS-CRP's discriminating power being significantly higher [ASDAS-CRP: 2.90 (95\% CI 2.35-3.61); ASDAS-ESR: 1.60 (95\% CI 1.16-2.16), both $\mathrm{p}<0.001]$. Moreover, ASDAS-CRP outperformed BASDAI which had a SMD of $2.16(95 \% \mathrm{CI}$ 1.62-2.71). Also, BASFI showed a good discriminating ability (SMD: 1.07 (95\% CI 1.07-2.06), p < $0.001)$. In contrast, ESR and CRP showed poor discriminating abilities (SMD $<0.50 ; \mathrm{p}>0.05$ ).

According to the CRP values, $54 \%$ of the axSpA patients had high disease activity $(\mathrm{CRP} \geq 6 \mathrm{mg} / \mathrm{l})$ and $46 \%$ of the patients had low disease activity $(\mathrm{CRP}<$
$6 \mathrm{mg} / \mathrm{l})$. Again, the variable that discriminated the best between disease activity states was ASDASCRP (SMD = 2.34 (95\% CI 1.78-2.89); $<<0.001)$. Both ASDAS versions outperformed BASDAI, as well as all the other indices of disease activity. Moreover, the SMDs of ASDAS-CRP was significantly higher than the SMD of BASDAI.

Figure 1 shows the ROC curve of the three composite disease activity indices by using the $\mathrm{PtGA} \geq 5$ as an external criterion of high disease activity state. For ASDAS-CRP, ASDAS-ESR and BASDAI the AUC were 0.91 (95\% CI 0.84-0.97), 0.89 (95\% CI $0.81-0.97)$, and 0.92 (95\% CI 0.87-0.99), respectively (all $\mathrm{p}<0.001)$. Optimal cut-offs for ASDAS values as indicators of high disease activity were calculated based on ROC analyses. A value of $>2.7$ for ASDAS-CRP score had a sensitivity of $79 \%$, a specificity of $89 \%$, a positive predictive value of $93 \%$ and negative predictive value of $70 \%$. Similarly, a value of ASDAS-ESR score $>2.5$ had a sensitivity of $79 \%$, a specificity of $83 \%$, a positive predictive value of $90 \%$ and negative predictive value of $69 \%$.

Performing the ROC analysis of the aforementioned indices by using the CRP level $\geq 6 \mathrm{mg} / \mathrm{l}$ as definition of high disease activity state, the AUCs for ASDAS-CRP, ASDAS-ESR and BASDAI were 0.81 (95\% CI 0.71-0.89); $\mathrm{p}<0.001,0.77$ (95\% CI $0.67-0.87) ; \mathrm{p}<0.001$ and 0.66 (95\% CI 0.54-0.78); $\mathrm{p}=0.01$, respectively.

TABLE 4. Discrimination between axSpA patients with high and low disease activity states*

\begin{tabular}{|c|c|c|c|c|c|c|}
\hline & \multicolumn{3}{|c|}{ PtGA score $(0-10)$} & \multicolumn{3}{|c|}{ CRP (mg/l) } \\
\hline & $\begin{array}{c}\text { PtGA }<5 \\
(n=33)\end{array}$ & $\begin{array}{c}\text { PtGA } \geq 5 \\
(n=52)\end{array}$ & $\begin{array}{c}\text { SMD } \\
(95 \% \mathrm{Cl})\end{array}$ & $\begin{array}{l}\text { CRP < } 6 \\
(n=39)\end{array}$ & $\begin{array}{l}\text { CRP } \geq 6 \\
(n=46)\end{array}$ & $\begin{array}{c}\text { SMD } \\
(95 \% \mathrm{Cl})\end{array}$ \\
\hline ASDAS-CRP & $2.3(0.8)$ & $3.9(0.1)$ & $\begin{array}{c}2.90 \\
(2.35-3.61)\end{array}$ & $2.6(0.1)$ & $3.9(1.1)$ & $\begin{array}{c}2.34 \\
(1.78-2.89)\end{array}$ \\
\hline ASDAS-ESR & $2.1(0.9)$ & $3.7(1.0)$ & $\begin{array}{c}1.60 \\
(1.16-2.16)\end{array}$ & $2.5(0.9)$ & $3.6(1.2)$ & $\begin{array}{c}1.02 \\
(0.57-1.48)\end{array}$ \\
\hline BASDAI & $2.5(1.5)$ & $6.3(1.9)$ & $\begin{array}{c}2.16 \\
(1.62-2.71) \\
\end{array}$ & $4.2(2.5)$ & $5.4(2.5)$ & $\begin{array}{c}0.48 \\
(0.05-0.91)\end{array}$ \\
\hline PGA & $2.7(1.1)$ & $7.7(1.7)$ & - & $5.1(2.8)$ & $6.5(2.8)$ & $\begin{array}{c}0.5 \\
(0.07-0.93)\end{array}$ \\
\hline ESR & 18.9 (17.9) & $27.5(24.3)$ & $\begin{array}{c}0.39 \\
(0.05-0.83) \\
\end{array}$ & $4.2(2.5)$ & $5.4(2.5)$ & $\begin{array}{c}0.48 \\
(0.05-0.91) \\
\end{array}$ \\
\hline CRP & $16.5(22.3)$ & $21.0(21.0)$ & $\begin{array}{c}0.21 \\
(0.22-0.65)\end{array}$ & $4.9(1.1)$ & $31.1(23.1)$ & - \\
\hline BASFI & $2.4(2.3)$ & $5.9(2.2)$ & $\begin{array}{c}1.07 \\
(1.07-2.06)\end{array}$ & $4.1(2.4)$ & $5.0(2.9)$ & $\begin{array}{c}0.33 \\
(0.09-0.76)\end{array}$ \\
\hline
\end{tabular}

* Disease activity states are based on patient's global assessment (PtGA) score: high $\geq 5$ versus low $<5$ and

C-reactive protein (CRP): high $\geq 6 \mathrm{mg} / \mathrm{l}$ versus low $<6 \mathrm{mg} / \mathrm{l}$.

Values are shown as mean (SD).

$\mathrm{SMD}$, standardized mean difference; $\mathrm{Cl}$, confidence interval.

ASDAS, Ankylosing Spondylitis Disease Activity Score; Erythrocyte Sedimentation Rate;

BASDAI, Bath Ankylosing Spondylitis Disease Activity Index; PtGA, Patient Global Assessement;

BASFI, Bath Ankylosing Spondylitis Disease Functional Index. 


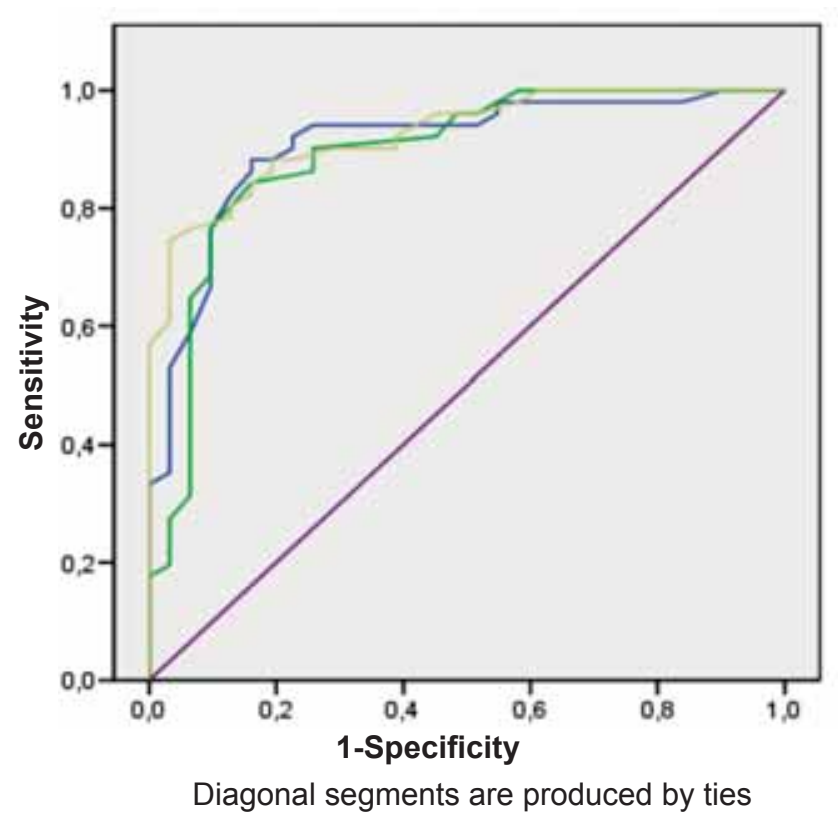

Source of the Curve

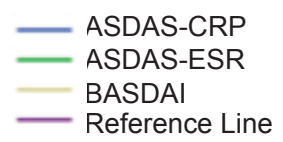

FIGURE 1. ROC curves for the composite disease activity indices (ASDAS-CRP, ASDAS-ESR and $B A S D A l)$, by using patient's global assessment as external indicator

\section{DISCUSSION}

In a cohort of patients with axSpA we found that ASDAS had good correlation with other indices of disease activity and a higher discriminating power between patients with high and low disease activity than conventional measures. Our results suggest that ASDAS is a valid tool for disease activity assessment in daily clinical practice.

Given the complexity of the disease it is unlikely that individual variables are appropriate for assessing disease activity in axSpA patients. Among the composite indices, BASDAI was the most widely used measure of disease activity in axSpA. A recent review discussed the limits of this instrument that measures only a part of disease activity, is fully patient-oriented, does not weight individual clinical manifestations (3). Patients and doctors have different perspectives of the disease and the aforementioned questionnaire does not provide an objective basis for disease assessment (5). On the contrary, the ASDAS, a relatively new validated assessment tool which combines patient-reported measures with acute phase reactants, reflects disease activity from both patient and doctor perspective. Several studies reported that ASDAS is able to differentiate patients with various levels of disease activity and those with different levels of change (6-15), so it turned out to be a highly discriminatory tool, and the best method to use in clinical trials (16). A recent longitudinal study demonstrated that markers of disease activity were associated with structural damage as assessed by mSASSS (modified Stokes AS Scoring System). In this respect, ASDAS outperformed all the other measures of disease activity, including BASADAI and CRP (24). At the same time, it proved highest responsiveness compared to BASDAI and CRP in what concerns changes in MRI inflammation $(8,16)$. ASDAS performed better in most of the studies in AS patients and was relevant also in early spondyloarthritis, nraxSpA, peripheral spondyloarthritis and axial psoriatic arthritis $(11,25)$. Until recently, most therapeutic trials used BASDAI as a tool to select candidates for anti-TNF $\alpha$ agents, as well as for monitoring therapeutic response. However, recent studies are more and more debating upon the validity of this approach, emphasizing that ASDAS might be a more appropriate tool for selection of patients for anti-TNF $\alpha$ treatment and for monitoring treatment response (12-14).

Our study compared the performance of the ASDAS score and of the conventional measures of assessing disease activity in a cohort of unselected axial SpA patients monitored in daily clinical practice. In line with the two original studies $(6,7)$ that validated ASDAS in three different cohorts (the Outcome in Ankylosing Spondylitis International Study - OASIS cohort, the Norwegian register NORDMARD and a cohort from a randomized clinical trial with TNF blockers), we have found good correlations between both ASDAS versions and other patient-reported measurements of disease activity. We also found moderate correlations between ASDAS and objective markers of disease activity (ESR and CRP). Similar results were reported in other observational and therapeutic studies $(8-11,15)$.

Using different definitions for disease activity, we have shown that both ASDAS versions had better discriminating ability in patients with axSpA than conventional measures, including PtGA, CRP and ESR. Interestingly, even when PtGA was used as an external indicator of disease activity state, ASDASCRP outperformed BASDAI. In the aforementioned situation, BASDAI performed better than the ASDAS-ESR version. In our study, ASDAS-CRP had the highest discriminating power among all markers of disease activity. Moreover, in our cohort, ASDAS- 
CRP showed a much better discriminating ability than in other studies $(6,7,11,15)$. The aforementioned results highlight the ASAS recommendation to preferably use the ASDAS-CRP version and, only when CRP is not available, use the ASDAS-ESR version as an alternate (7). In contrast, other researchers found little or no difference in performance between the two versions of ASDAS $(11,15)$. On the whole, the studies concerning the discriminating ability of various measures of disease activity showed that ASDAS performs at least equally well as BASDAI, if not better (6-15). Van der Heijde et al. (7) reported that the only situation in which BASDAI outperformed the ASDAS versions was the distinction between being versus not being in acceptable symptom state according to the patient (PASS).

It was shown that loss of function and disability in axSpA patients are due to both persistent inflammation and structural damage (26). Our observation that BASFI, the most widely used functional index, showed good correlation with composite indices of disease activity (ASDAS-CRP, ASDAS-ESR and BASDAI) and had good discriminating ability between patients with high and low disease activity, suggests that function was significantly influenced by disease activity in our cohort.

Our results enabled us to estimate the different ASDAS levels and their meaning: e.g. mean values around 4 correspond to a PtGA and a BASDAI score of at least 6 . Similar results were reported by van der Heijde et al. (7). We also performed ROC analysis to find the best cut-off value of ASDAS scores for differentiating between high and low disease activity. The calculated ASDAS cut-offs in our axSpA pa- tients were relatively similar to the Assessment of Spondyloarthritis International Society (ASAS) endorsed cut-offs (17).

One of the limitations of our single-centre, cross sectional study is the potential selection bias as we addressed only patients referred to a tertiary Rheumatology centre who could not be always consecutively included. Moreover, our cohort was heterogeneous as it comprised AS and nr-axSpA patients with various treatments, including anti-TNF $\alpha$ agents. However, we included only patients which fulfilled the imaging arm of ASAS criteria for classification of $\operatorname{axSpA}$, and patients from both groups had similar characteristics in terms of disease activity. Due to the small number of patients with nr-axSpA we were not able to examine the indices' performance in these patient subgroups.

To conclude, our study has shown that ASDAS versions had higher discriminating ability than conventional measures to differentiate between patients with axSpA in terms of high and low disease activity. Our findings suggest that ASDAS is a valid and reliable assessment tool for axSpA patients in daily clinical practice. However, in order to prove ASDAS feasibility it is necessary to carry out further prospective longitudinal studies on larger populations of axSpA with various degrees of activity and severity.

\section{Acknowledgments}

This research was conducted under the frame of European Social Fund, Human Resources Development Operational Programme 2007-2013, project no. POSDRU/159/1.5/S/138776.

\section{$\overline{\text { REFERENCES }}$}

1. Braun J., Pham T., Sieper J. et al. ASAS Working Group: International ASAS consensus statement for the use of anti-tumour necrosis factor agents in patients with ankylosing spondylitis. Ann Rheum Dis 2003; 62:817-24.

2. van der Heijde, van der Linden S., Bellamy N. et al. Which domains should be included in a core set for endpoints in ankylosing spondylitis ? Introduction to the ankylosing spondylitis module of OMERACT IV. J Rheumatol 1999; 26:945-7.

3. Machado P., van der Heijde D. How to measure disease activity in axial spondyloarthritis? Curr Opin Rheumatol 2011; 23:339-45.

4. Braun J., Kiltz U., Baraliakos X. et al. Optimisation of rheumatology assessments - the actual situation in axial spondyloarthritis including ankylosing spondylitis. Clin Exp Rheumatol 2014; 32(Suppl.85):S96-S104.
5. Spoorenberg A., van Tubergen A., Landewé R. et al. Measuring disease activity in ankylosing spondylitis: patients and physician have different perspectives. Rheumatology 2005; 44:789-95.

6. Lukas C., Landewe R., Sieper J. et al. Development of an ASAS-endorsed disease activity score (ASDAS) in patients with ankylosing spondylitis. Ann Rheum Dis. 2009 Jan; 68(1):18-24

7. van der Heijde D., Lie E., Kvien T.K. et al. The ASDAS is a highly discriminatory ASAS-endorsed disease activity score in patients with ankylosing spondylitis. Ann Rheum Dis 2009; 68:1811-8.

8. Pedersen S.J., Sorensen I.J., Hermann K.G. et al. Responsiveness of the Ankylosing Spondylitis Disease Activity Score (ASDAS) and clinical and MRI measures of disease activity in a 1-year follow-up study of patients with axial spondyloarthritis treated with tumour necrosis factor alpha inhibitors. Ann Rheum Dis 2010; 69:1065-71. 
9. Aydin S.Z., Can M., Atagunduz P. et al. Active disease requiring TNF-alpha-antagonist therapy can be well discriminated with different ASDAS sets: a prospective, follow-up of disease activity assessment in ankylosing spondylitis. Clin Exp Rheumatol 2010; 28:752-5.

10. Popescu C., Trandafir M., Badica A.M. et al. Ankylosing spondylitis functional and activity indices in clinical practice. $J$ Med Life 2014; 7:78-83.

11. Espartero-Fernández C., de Miguel E., Loza E., et al. Validity of the Ankylosing Spondylitis Disease Activity Score (ASDAS) in patients with early spondyloarthritis from the Esperanza programme. Ann Rheum Dis 2014; 73:1350-5.

12. van der Heijde, Braun J., Dougados M., et al. Sensitivity and discriminatory ability of the Ankylosing Spondylitis Disease Activity Score (ASDAS) in patients treated with etanercept or sulphasalazine in the ASCEND trial. Rheumatology (Oxford) 2012; 51:1894-905.

13. Fagerli K.M., Lie E., van der Heijde D. et al. Selecting patients with ankylosing spondylitis for TNF inhibitor therapy: comparison of ASDAS and BASDAI eligibility criteria. Rheumatology 2012; 51:1479-83.

14. Vastesaeger N., Cruyssen B.V., Mulero J. et al. REGISPONSER WORKING GROUP. ASDAS high disease activity versus BASDAI elevation in patients with ankylosing spondylitis as selection criterion for anti-TNF therapy. Rheumatol Clin 2014; 10:204-9.

15. Machado P., Landewé R. Spondyloarthritis: Is it time to replace BASDAI with ASDAS? Nat Rev Rheumatol 2013; 9:388-90.

16. Machado P. Landewe R., Lie E. et al. Ankylosing Spondylitis Disease Activity Score (ASDAS): defining cut-off values for disease activity states and improvement scores. Ann Rheum Dis 2011; 70:47-53.

17. Smolen J.S., Braun J., Dougados M., et al. Treating spondyloarthritis, including ankylosing spondylitis and psoriatic arthritis, to target: recommendations of an international task force. Ann Rheum Dis. Published Online First: 8 June 2013; doi:10.1136/ annrheumdis-2013-203419.

18. Rudwaleit M., van der Heijde D., Landewé R. et al. The development of Assessment of SpondyloArthritis international Society classification criteria for axial spondyloarthritis (part II): validation and final selection. Ann Rheum Dis 2009; 68:777-83.

19. Jenkinson T.R., Mallorie P.A., Whitelock H.C. et al. Defining spinal mobility in ankylosing spondylitis (AS). The Bath AS Metrology Index. J Rheumatol 1994;21:1694-8.

20. Calin A., Garrett S., Whitelock H. et al. A new approach to defining functional ability in ankylosing spondylitis: The Bath Ankylosing Spondylitis Functional Index. J Rheumatol 1994; 21:2281-5.

21. Garrett S., Jenkinson T., Kennedy L.G. et al. A new approach to defining disease status in ankylosing spondylitis: The Bath Ankylosing Spondylitis Disease Activity Index. J Rheumatol 1994; 21:2286-91.

22. Van Der Linden S., Valkenburg H.A., Cats A. Evaluation of diagnostic criteria for ankylosing spondylitis. A proposal for modification of the New York criteria. Arthritis Rheum 1984; 27:361-8.

23. Ramiro S., van der Heijde D., van Tubergen A. et al. Higher disease activity leads to more structural damage in the spine in ankylosing spondylitis: 12-year longitudinal data from the OASIS cohort. Ann Rheum Dis 2014; 73:1455-61.

24. Eder L., Chandran V., Shen H., et al. Is ASDAS better than BASDAl as a measure of disease activity in axial psoriatic arthritis? Ann Rheum Dis 2010;69:2160-4.

25. Machado P., Landewé R., Braun J. et al. Both structural damage and inflammation of the spine contribute to impairment of spinal mobility in patients with ankylosing spondylitis. Ann Rheum Dis 2010; 69:1465-70. 